Article

\title{
Novel Bioactive Paulomycin Derivatives Produced by Streptomyces albus J1074
}

\author{
Jorge Fernández-De la Hoz (iD), Carmen Méndez, José A. Salas and Carlos Olano* \\ Departamento de Biología Funcional e Instituto Universitario de Oncología del Principado de \\ Asturias (I.U.O.P.A), Universidad de Oviedo, C/Julian Claveria s/n, 33006, Oviedo (Asturias), Spain; \\ jorgefhoz@gmail.com (J.F.-D.1.H.); cmendezf@uniovi.es (C.M.); jasalas@uniovi.es (J.A.S.) \\ * Correspondence: olanocarlos@uniovi.es; Tel.: +34-985-105-288
}

Received: 25 September 2017; Accepted: 17 October 2017; Published: 18 October 2017

\begin{abstract}
Four novel paulomycin derivatives have been isolated from S. albus J1074 grown in MFE culture medium. These compounds are structural analogs of antibiotics $273 a_{2 \alpha}$ and $273 a_{2 \beta}$ containing a thiazole moiety, probably originated through an intramolecular Michael addition. The novel, thiazole, moiety-containing paulomycins show a lower antibiotic activity than paulomycins A and B against Gram-positive bacteria. However, two of them show an improved activity against Gram-negative bacteria. In addition, the four novel compounds are more stable in culture than paulomycins A and B. Thus, the presence of an N-acetyl-L-cysteine moiety linked to the carbon atom of the paulic acid isothiocyanate moiety, via a thioester bond, and the subsequent intramolecular cyclization of the paulic acid to generate a thiazole heterocycle confer to paulomycins a higher structural stability that otherwise will conduce to paulomycin degradation and into inactive paulomenols.
\end{abstract}

Keywords: antibiotic $273 \mathrm{a}_{2}$; paulic acid; paulomenol; structural analogue; thiazole moiety

\section{Introduction}

Streptomyces albus J1074 is a derivative of S. albus G, defective in both the restriction and modification enzymes of the SalI system [1] and widely used as a host for the expression of Streptomyces secondary metabolite gene clusters [2,3]. Genome mining, genetic manipulation, and the activation of secondary metabolite gene clusters studies applied to S. albus J1074 have revealed its ability to produce, under different conditions and manipulation techniques, several carotenoids [4], hybrid polyketide-non-ribosomal peptides antimycins and 6-epi-alteramides [5], type I polyketides candicidins [5], non-ribosomal peptide indigoidine [5], and non ribosomal peptides surugamides [6]. In addition, S. albus J1074, as well as the parental strain S. albus G, produces glycosylated compounds paulomycin $A, B$, and $E[5,7]$, and their derivatives paulomenol $A$ and $B$, generated by the spontaneous loss of the paulic acid moiety [5]. The S. albus J1074 paulomycin biosynthesis gene cluster has been characterized, establishing a biosynthesis pathway [8].

Paulomycins A and B, antibiotics containing an isothiocyanate group (paulic acid) and mainly active against Gram-positive bacteria, were initially isolated from Streptomyces paulus strain $273[9,10]$. S. paulus produces paulomycins as a family of compounds that include paulomycin A, A2, B, C, D, $\mathrm{E}$, and $\mathrm{F}$ [11], O-demethylpaulomycins $\mathrm{A}$ and $\mathrm{B}$, paulomenol $\mathrm{A}$ and $\mathrm{B}$, hydrogen sulfide adducts of paulomycin A and B [12], antibiotics $273 \mathrm{a}_{2 \alpha}$ and $273 \mathrm{a}_{2 \beta}$, and paldimycin $\mathrm{A}$ and $\mathrm{B}$, derivatives of paulomycin A and paulomycin B containing one or two $N$-acetyl-L-cysteine groups, respectively $[13,14]$. Antibiotic activity of paldimycins was assessed in vitro against Gram-positive bacteria and found comparable to that of vancomycin [15]. On the other hand, paulomenols A and B lack antibacterial activity, pointing to paulic acid as determinant of the antibiotic properties of paulomycins and paldimycins [12]. 
Different approaches have been used for the generation of derivatives of known compounds through combinatorial biosynthesis [16,17]. Thus, paulomycin derivatives have been generated carrying modifications in the L-paulomycose moiety [8]. Other methods involve the enhancement of the expression of the gene cluster in order to identify novel natural products [6]. This can be accomplished by several systems, such as the systematic alteration of the culture media composition or cultivation parameters to elevate production titers of compounds and encourage the production of a wider range of natural products from a microorganism. This method is known as OSMAC (One Stain Many Compounds) [18]. In this work, we describe the identification and structural characterization of several natural paulomycin derivatives produced by S. albus J1074 using the OSMAC approach.

\section{Results}

\subsection{Identification of Compounds}

In our laboratory, production of secondary metabolites by S. albus J1074, including paulomycins, has been routinely monitored using R5A as production medium [5,8]. However, purification of different paulomycin derivatives generated by combinatorial biosynthesis approaches was accomplished in MFE medium where the production of some secondary metabolites by S. albus J1074 was higher than in R5A [8]. Comparison of S. albus J1074 grown in MFE medium during 96 h with S. albus B29, mutant strain blocked in early steps of paulomycins biosynthesis [5], led to the identification or four novel compounds (1-4) probably derived from the paulomycin pathway (Figure 1). These compounds show Ultra Performance Liquid Chromatography (UPLC) retention times of 4.29 (1), 4.32 (2), 4.53 (3), and 4.56 (4) min, paulomenol-like absorption spectrum with maxima at 238 and $320 \mathrm{~nm}$, and masses of $m / z$ 936, 936, 950, and $950[\mathrm{M}+\mathrm{H}]^{+}$, respectively.

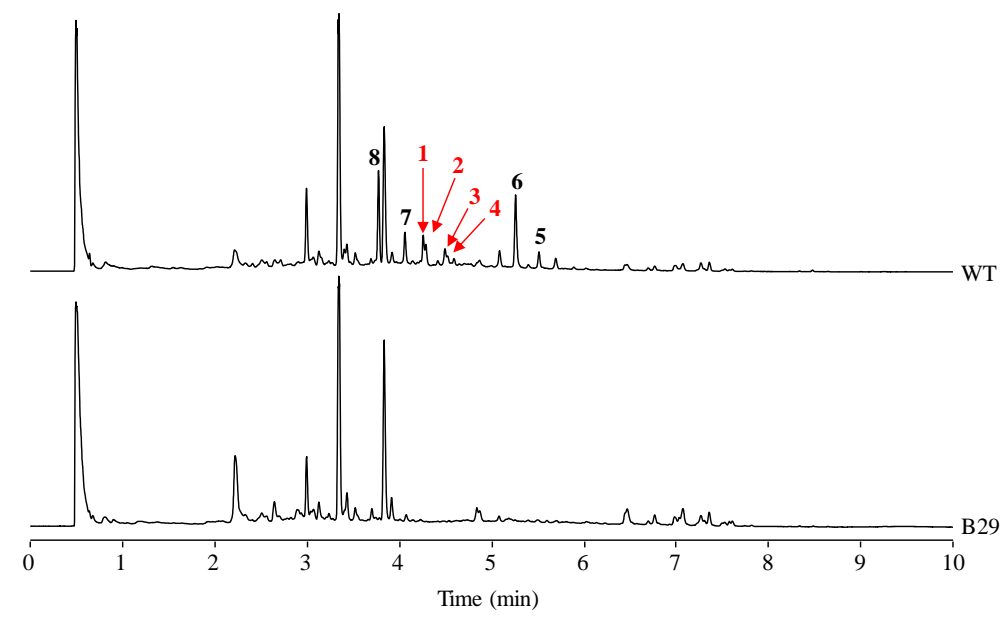

Figure 1. UPLC chromatograms, monitored at $238 \mathrm{~nm}$, of S. albus J1074 (wt) and S. albus B29 (B29). Extracts were generated from cultures of the strains in MFE liquid medium during $96 \mathrm{~h}$. Labeled peaks correspond to novel paulomycin derivatives (1-4), paulomycin A (5), paulomycin B (6), paulomenol A (7), and paulomenol B (8).

\subsection{Structural Characterization of Novel Paulomycins}

Peak 1 (Figure 1) was obtained as a brownish amorphous powder. The LC-DAD-HRMS run revealed the presence of two main compounds with retention mobility of 3.55 and 3.90 min, respectively (Figure S1). The main component, compound $\mathbf{1}$ (eluting at $3.55 \mathrm{~min}$ ), was assigned a molecular formula of $\mathrm{C}_{38} \mathrm{H}_{53} \mathrm{~N}_{3} \mathrm{O}_{20} \mathrm{~S}_{2}$ based on the molecular ion peak $[\mathrm{M}+\mathrm{H}]^{+}$observed at 936.2739 (calcd. for $\mathrm{C}_{38} \mathrm{H}_{54} \mathrm{~N}_{3} \mathrm{O}_{20} \mathrm{~S}_{2}{ }^{+}=936.2739$ ) (Figure S2). On the other hand, the secondary component, compound $\mathbf{1}^{\prime}$ (eluting at $3.90 \mathrm{~min}$ ), was assigned a molecular formula of $\mathrm{C}_{38} \mathrm{H}_{51} \mathrm{~N}_{3} \mathrm{O}_{19} \mathrm{~S}_{2}$ based on the molecular ion peak $[\mathrm{M}+\mathrm{H}]^{+}$observed at 918.2636 (calcd. for $\mathrm{C}_{38} \mathrm{H}_{52} \mathrm{~N}_{3} \mathrm{O}_{19} \mathrm{~S}_{2}{ }^{+}=918.2631$ ) (Figure S2). 
Both compounds are clearly related to each other, the latter being a dehydration product of the former. A search in the Dictionary of Natural Products indicates that the molecular formula of compound 1 might correspond to antibiotic $273 \mathrm{a}_{2} \beta$, a compound related to paulomycins. The UV (DAD) (Figure S3) shows strong resemblance to that reported for antibiotic 273a 2 (both $\alpha$ and $\beta$ ) $[12,13]$.

To establish the identity of the main compound 1 (Table 1 ; Figure 2) a ${ }^{1} \mathrm{H}$ NMR spectrum and a set of 2D NMR spectra (including COSY, TOCSY, NOESY, HSQC and HMBC) were acquired (Figures S4-S7). The proton and HSQC confirmed the relationship with $273 \mathrm{a}_{2} \beta$, although there were important differences which indicated that compound 1 was novel. Being related to paulomycin it was not surprising that many of the observed signals showed strong resemblance to those displayed by paulomycin $\mathrm{F}$ and other paulomycin derivatives previously described [8]. In depth interpretation of the observed correlations allowed establishing the structure of compound 1 . The connectivity of compound 1 is like that of antibiotic $273 \mathrm{a}_{2 \beta}$, but the terminal $N$-acetylcysteine group is connected in this case via a heterocyclic ring (thiazoline) rather than forming a dithiocarbamate. In fact, compound $\mathbf{1}$ could be considered as an intramolecular Michael addition derivative of antibiotic $273 \mathrm{a}_{2} \beta$; the sulfur nucleophile in the thioenol form of the dithiocarbamate moiety of antibiotic $273 \mathrm{a}_{2 \beta}$ is attacking the $\mathrm{C}_{\beta}$ of the $\alpha$, $\beta$ unsaturated amino acid moiety and rendering a dihydrothiazol (thiazoline) ring (Figure S8). The chirality of the $N$-acetylcysteine moiety was arbitrarily assigned an $S$ configuration assuming it directly derived from standard proteinogenic L-cysteine. The syn relative configuration at positions $2^{\prime \prime}$ and $3^{\prime \prime}$ is based on the strong key NOE observed between the protons at these positions. The observed coupling constant for $\mathrm{H}-2^{\prime \prime}$ (7.5 Hz) also agrees with a syn configuration. On the other hand, the expected $\beta$ anomeric configuration found for the monosaccharide unit in antibiotics $273 \mathrm{a}_{2 \beta}$ [14] is observed for compound 1 based on the coupling constant of the anomeric proton (br d, $3.5 \mathrm{~Hz}$ ).

Table 1. NMR data ( $\delta$ in ppm) for compound 1 (DMSO- $\left.d_{6}, 500 \mathrm{MHz}, 24^{\circ} \mathrm{C}\right)$. Carbon chemical shifts derived from HSQC and HMBC spectra.

\begin{tabular}{|c|c|c|c|c|c|}
\hline Position & $\delta\left({ }^{13} \mathrm{C}\right)$ & $\delta\left({ }^{1} \mathrm{H}\right),($ Mult, $J$ in $\mathrm{Hz})$ & Position & $\delta\left({ }^{13} \mathrm{C}\right)$ & $\delta\left({ }^{1} \mathrm{H}\right),(\mathrm{Mult}, J$ in $\mathrm{Hz})$ \\
\hline 1 & n.d. & - & $1^{\prime}$ & 98.5 & $4.89($ br d, 3.5) \\
\hline 2 & 99.9 & - & $2^{\prime}$ & 30.7 & $2.04(\mathrm{~m}) 1.77(\mathrm{td}, 12.3,3.6)$ \\
\hline 3 & 159.9 & - & $3^{\prime}$ & 75.0 & $3.43(\mathrm{~m})$ \\
\hline 4 & 189.2 & - & $3^{\prime} \alpha$ & 57.1 & $3.24(\mathrm{~s})$ \\
\hline 5 & 48.9 & $3.27(\mathrm{~m}) 3.00(\mathrm{~d}, 16.2)$ & $4^{\prime}$ & 73.9 & - \\
\hline 6 & 78.2 & - & $5^{\prime}$ & 67.5 & $4.41(\mathrm{~m})$ \\
\hline 7 & 198.7 & - & $6^{\prime}$ & 16.4 & $1.10(\mathrm{~m})$ \\
\hline 8 & 77.7 & $3.64(\mathrm{~d}, 10.0)$ & $7^{\prime}$ & 69.9 & 5.27 (quart., 6.8) \\
\hline 9 & 69.2 & $3.48(\mathrm{~m})$ & $8^{\prime}$ & 16.5 & $1.18(\mathrm{~d}, 6.7)$ \\
\hline 10 & 74.5 & $4.08(\mathrm{br} \mathrm{t})$ & $9^{\prime}$ & 176.5 & - \\
\hline 11 & 70.7 & $4.66(\mathrm{dd}, 10.2,1.8)$ & $10^{\prime}$ & 34.3 & $2.55(\mathrm{~m})$ \\
\hline 12 & 71.8 & $4.01(\mathrm{dt}, 9.9,3.4)$ & $11^{\prime}$ & 19.6 & $1.08(\mathrm{~m})$ \\
\hline 13 & 62.9 & $3.77(\mathrm{~m})$ & $12^{\prime}$ & 19.8 & $1.13(\mathrm{~d}, 7.0)$ \\
\hline 14 & 171.0 & - & $1^{\prime \prime}$ & 168.5 & - \\
\hline \multirow[t]{10}{*}{15} & 21.2 & $1.96(\mathrm{~s})$ & $2^{\prime \prime}$ & 80.3 & $5.04(\mathrm{~d}, 7.5)$ \\
\hline & & & $3^{\prime \prime}$ & 49.8 & $4.36(\mathrm{~m})$ \\
\hline & & & $4^{\prime \prime}$ & 16.5 & $1.10(\mathrm{~m})$ \\
\hline & & & $5^{\prime \prime}$ & 167.8 & - \\
\hline & & & $1^{\prime \prime \prime}$ & 172.3 & - \\
\hline & & & $2^{\prime \prime \prime}$ & 52.6 & $4.45(\mathrm{~m})$ \\
\hline & & & $3^{\prime \prime \prime}$ & 34.2 & $3.62(\mathrm{~m}) 3.26(\mathrm{~m})$ \\
\hline & & & $4^{\prime \prime \prime}$ & 170.3 & - \\
\hline & & & $5^{\prime \prime \prime}$ & 23.2 & $1.85(\mathrm{~s})$ \\
\hline & \multicolumn{2}{|c|}{$\mathrm{NH}_{2}$} & & - & 8.30 \\
\hline
\end{tabular}

The secondary component $\mathbf{1}^{\prime}$ (Figure 2) is proposed to be the dehydration product obtained by a water loss at positions 5 and 6, generating the corresponding quinone ring. Additionally, an HSQC 
signal observed at $6.91 \mathrm{ppm}\left({ }^{1} \mathrm{H}\right)$ and $132.2 \mathrm{ppm}\left({ }^{13} \mathrm{C}\right)$ (Figure S5) was a clear diagnostic of the new double bound (between positions 5 and 6) in the secondary product. It was not possible to prepare an NMR table for this secondary compound, although all the positions but those close to the new double bond are expected to resonate at the same frequency as the main compound in this sample.

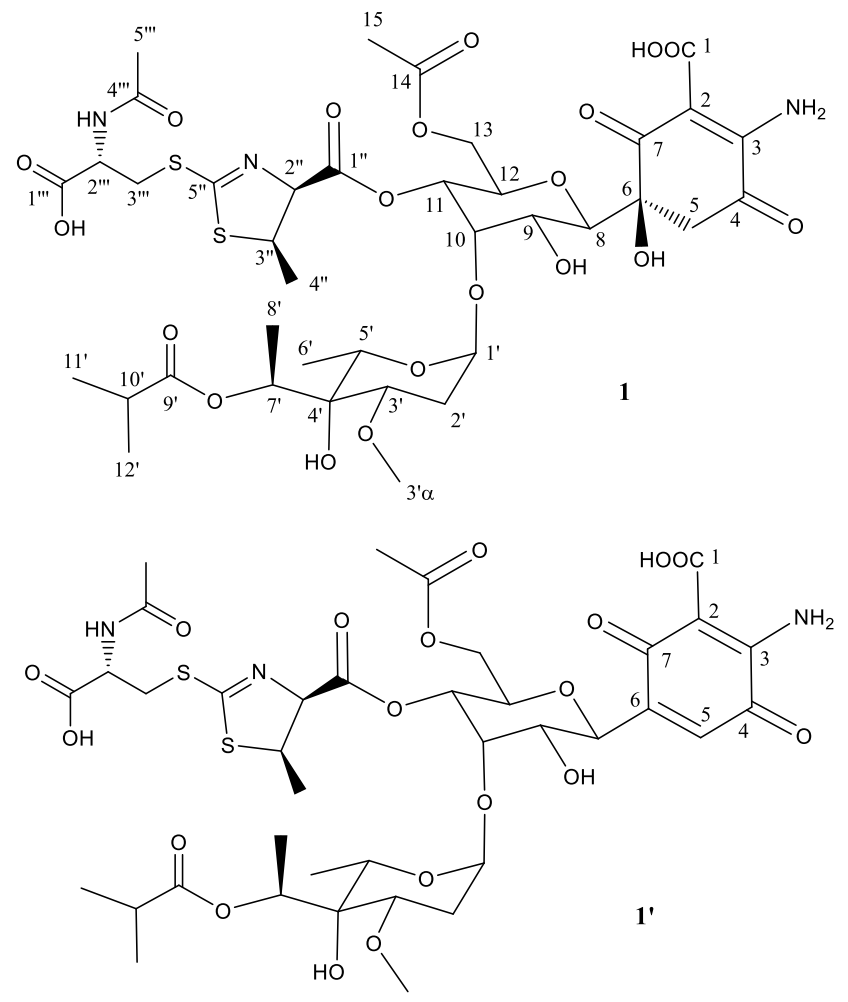

Figure 2. Structure of compound 1 deduced from ${ }^{1} \mathrm{H}$ - and ${ }^{13} \mathrm{C}-\mathrm{NMR}$ data and proposed structure of secondary product compound $\mathbf{1}^{\prime}$ after abstraction of one molecule of $\mathrm{H}_{2} \mathrm{O}$.

Peak 2 (Figure 1) was obtained as a brownish amorphous powder. The LC-DAD-HRMS run revealed the presence of two main compounds with retention mobility of 3.55 and 3.91 min, respectively (Figure S9). Both components showed identical retention time, DAD, and HRMS spectra (Figures S10 and S11) as the compounds detected in peak 1 . Thus, having the same molecular formula, it was very likely that compounds $\mathbf{2}$ and $\mathbf{2}^{\prime}$ might be isomers (probably stereoisomers) of compounds $\mathbf{1}$ and $\mathbf{1}^{\prime}$, or maybe the actual antibiotic $273 \mathrm{a}_{2 \beta}$ and its derivative after abstraction of one molecule of $\mathrm{H}_{2} \mathrm{O}$.

To unequivocally establish the identity of the main compound 2 (Table 2; Figure 3 ), a ${ }^{1} \mathrm{H}$ NMR spectrum and a set of 2D NMR spectra (including COSY, TOCSY, NOESY, HSQC, and HMBC) were acquired Figures S12 and S13). The proton and HSQC spectra immediately confirmed the relationship with compounds $\mathbf{1}$ and $\mathbf{1}^{\prime}$. Most signals were almost isochronous with those found in peak 1 , and the only significant chemical shift differences were localized in the signals of the thiazoline heterocycle, suggesting that in this case the antibiotic $273 \mathrm{a}_{2 \beta} \beta$ is the precursor and the proposed Michael addition has rendered the anti diastereomer in this ring. The weakness of NOESY correlation between protons at positions $2^{\prime \prime}$ and $3^{\prime \prime}$ and the observed coupling constant for $\mathrm{H}-2^{\prime \prime}(4.7 \mathrm{~Hz})$ confirmed the anti-relationship of these two protons. In compound 2, the key HMBC correlations that connect the $N$-acetylcysteine moiety to the thiazoline heterocycle are the same as those already found for peak 1 .

Similarly to peak 1 , the secondary component $\mathbf{2}^{\prime}$ is proposed to be the dehydration product obtained by a water loss at positions 5 and 6, generating the corresponding quinone. A key HSQC signal observed at $6.91 \mathrm{ppm}\left({ }^{1} \mathrm{H}\right)$ and $132.2 \mathrm{ppm}\left({ }^{13} \mathrm{C}\right)$ (Figure S13) provides a clear diagnostic of the new double bound (between positions 5 and 6 ) in the secondary product. 
Table 2. NMR data ( $\delta$ in ppm) for compound 2 (DMSO- $d_{6}, 500 \mathrm{MHz}, 24{ }^{\circ} \mathrm{C}$ ). Carbon chemical shifts derived from HSQC and HMBC spectra.

\begin{tabular}{cccccc}
\hline Position & $\boldsymbol{\delta}\left({ }^{\mathbf{1 3}} \mathbf{C}\right)$ & $\left.\boldsymbol{\delta} \mathbf{(}^{\mathbf{1}} \mathbf{H}\right),(\mathbf{M u l t}, \boldsymbol{J}$ in $\mathbf{H z})$ & Position & $\boldsymbol{\delta}\left({ }^{\mathbf{1 3}} \mathbf{C}\right)$ & $\boldsymbol{\delta}\left({ }^{\mathbf{1}} \mathbf{H}\right),(\mathbf{M u l t}, \boldsymbol{J}$ in $\mathbf{H z})$ \\
\hline 1 & n.d. & - & $1^{\prime}$ & 98.5 & $4.86(\mathrm{br} \mathrm{d}, 3.7)$ \\
2 & 99.9 & - & $2^{\prime}$ & 30.6 & $2.04(\mathrm{~m}) 1.78(\mathrm{~m})$ \\
3 & 159.9 & - & $3^{\prime}$ & 75.0 & $3.44(\mathrm{~m})$ \\
4 & 189.2 & - & $3^{\prime} \alpha$ & 57.1 & $3.24(\mathrm{~s})$ \\
5 & 48.7 & $3.26(\mathrm{~m}) 3.00(\mathrm{~d}, 16.2)$ & $4^{\prime}$ & 73.9 & - \\
6 & 78.2 & - & $5^{\prime}$ & 67.3 & $4.41(\mathrm{~m})$ \\
7 & 198.7 & - & $6^{\prime}$ & 16.3 & $1.10(\mathrm{~m})$ \\
8 & 77.6 & $3.62(\mathrm{~d}, 9.8)$ & $7^{\prime}$ & 69.8 & $5.27(\mathrm{quart} ., 6.8)$ \\
9 & 69.1 & $3.45(\mathrm{~m})$ & $8^{\prime}$ & 16.4 & $1.18(\mathrm{~d}, 6.7)$ \\
10 & 74.5 & $4.02(\mathrm{br} \mathrm{t})$ & $9^{\prime}$ & 176.2 & - \\
11 & 70.4 & $4.58(\mathrm{dd}, 10.1,2.0)$ & $10^{\prime}$ & 34.3 & $2.55(\mathrm{~m})$ \\
12 & 72.0 & $3.97(\mathrm{~m})$ & $11^{\prime}$ & 19.5 & $1.08(\mathrm{~m})$ \\
13 & 62.8 & $3.75(\mathrm{~m})$ & $12^{\prime}$ & 19.6 & $1.12(\mathrm{~m})$ \\
14 & 170.9 & - & $1^{\prime \prime}$ & 169.3 & - \\
15 & 21.1 & $1.97(\mathrm{~s})$ & $2^{\prime \prime}$ & 83.1 & $4.90(\mathrm{~d}, 4.7)$ \\
\hline & & $3^{\prime \prime}$ & 51.0 & $4.25(\mathrm{~m})$ \\
& & $4^{\prime \prime}$ & 22.5 & $1.38(\mathrm{~m})$ \\
& & $5^{\prime \prime}$ & 167.9 & - \\
& & $1^{\prime \prime \prime}$ & 172.2 & - \\
& & $2^{\prime \prime \prime}$ & 52.2 & $4.51(\mathrm{~m})$ \\
& & $3^{\prime \prime \prime}$ & 34.3 & $3.62(\mathrm{~m}) 3.23(\mathrm{~m})$ \\
& & $4^{\prime \prime \prime}$ & 170.2 & - \\
& & $5^{\prime \prime \prime}$ & 23.1 & $1.85(\mathrm{~s})$ \\
\hline
\end{tabular}

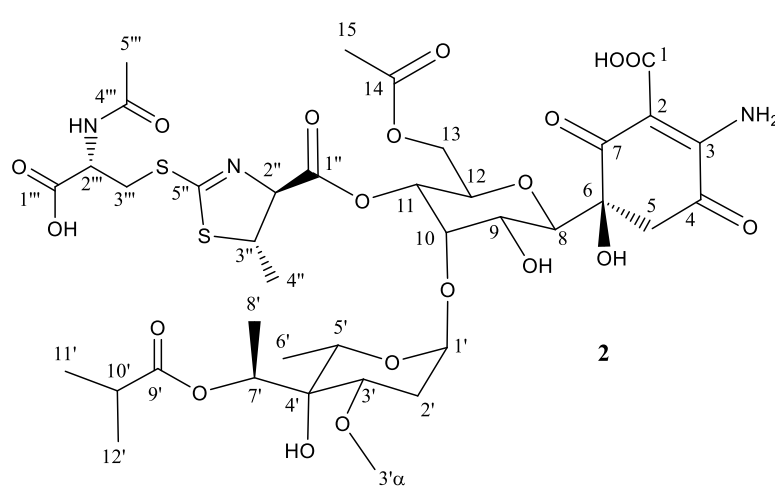

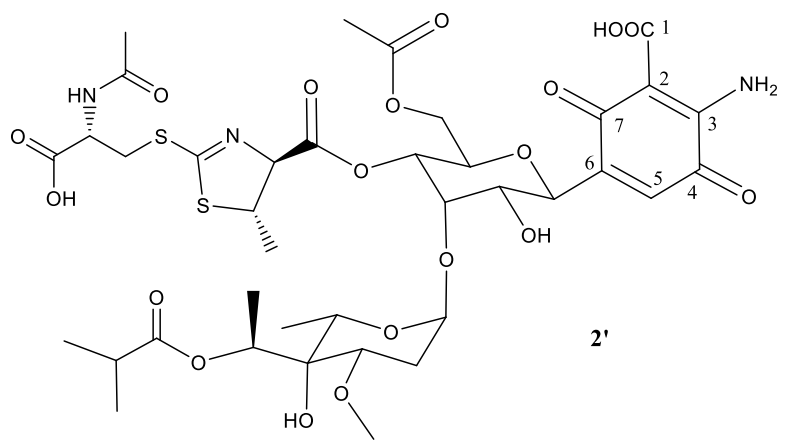

Figure 3. Structure of compound 2 deduced from ${ }^{1} \mathrm{H}$ - and ${ }^{13} \mathrm{C}-\mathrm{NMR}$ data and proposed structure of secondary product compound $\mathbf{2}^{\prime}$ after elimination of one molecule of $\mathrm{H}_{2} \mathrm{O}$.

Peak 3 (Figure 1) was obtained as a brownish amorphous powder. The LC-DAD-HRMS run revealed the presence of two main compounds with retention mobility of 3.77 and 4.06 min, respectively (Figure S14). The main component 3 (3.77 min) was assigned a molecular formula of $\mathrm{C}_{39} \mathrm{H}_{56} \mathrm{~N}_{3} \mathrm{O}_{20} \mathrm{~S}_{2}$ 
based on the molecular ion peak $[\mathrm{M}+\mathrm{H}]^{+}$observed at 950.2893 (calcd. for $\mathrm{C}_{39} \mathrm{H}_{56} \mathrm{~N}_{3} \mathrm{O}_{20} \mathrm{~S}_{2}{ }^{+}=950.2893$ ). On the other hand, the secondary component $3^{\prime}(4.07 \mathrm{~min})$ was assigned a molecular formula of $\mathrm{C}_{39} \mathrm{H}_{54} \mathrm{~N}_{3} \mathrm{O}_{19} \mathrm{~S}_{2}$ based on the molecular ion peak $[\mathrm{M}+\mathrm{H}]^{+}$observed at 938.2782 (calcd. for $\mathrm{C}_{39} \mathrm{H}_{54} \mathrm{~N}_{3} \mathrm{O}_{19} \mathrm{~S}_{2}{ }^{+}=$932.2787) (Figure S15). As already mentioned for peaks 1 and 2, both compounds are clearly related to each other, the latter being a dehydration product of the former. A search in the dictionary of natural products indicate that the molecular formula of compound 3 corresponds to antibiotic $273 \mathrm{a}_{2 \alpha}$ and the UV (DAD) (Figure S16) was identical to that observed for peaks 1 and 2, confirming their structural relationship.

To establish the identity of the main compound 3 (Table 3, Figure 4), a ${ }^{1} \mathrm{H}$ NMR spectrum and a set of 2D NMR spectra (including COSY, TOCSY, NOESY, HSQC and HMBC) were acquired (Figures S17 and S18). The proton and HSQC showed immediately the compound did not correspond to $273 \mathrm{a}_{2 \alpha}$ but to a compound identical to 1, but carrying an extra methylene group which, after analysis of the TOCSY and HMBC spectra, was found to be in the fatty acid. Thus, the structural difference between compounds 3 and $\mathbf{1}$ is the same as the difference between the antibiotics $273 a_{2 \alpha}$ and $273 a_{2 \beta}$. The chemical shifts observed for compound 3 were almost identical to compound $\mathbf{1}$ except for the fatty acid. The syn relative configuration at positions $2^{\prime \prime}$ and $3^{\prime \prime}$ was corroborated by the strong key NOE observed between the protons at these positions and the coupling constant of $7.5 \mathrm{~Hz}$ observed for $\left.\mathrm{H}-2^{\prime \prime}\right)$.

Table 3. NMR data ( $\delta$ in ppm) for compound 3 (DMSO- $d_{6}, 500 \mathrm{MHz}, 24{ }^{\circ} \mathrm{C}$ ). Carbon chemical shifts derived from HSQC and HMBC spectra.

\begin{tabular}{cccccc}
\hline Position & $\boldsymbol{\delta}\left({ }^{\mathbf{1 3}} \mathbf{C}\right)$ & $\boldsymbol{\delta}\left({ }^{\mathbf{1}} \mathbf{H}\right),(\mathbf{M u l t}, \boldsymbol{J}$ in $\mathbf{H z})$ & Position & $\boldsymbol{\delta}\left({ }^{\mathbf{1 3}} \mathbf{C}\right)$ & $\boldsymbol{\delta}\left({ }^{\mathbf{1}} \mathbf{H}\right),(\mathbf{M u l t}, \boldsymbol{J}$ in $\mathbf{H z})$ \\
\hline 1 & n.d. & - & $1^{\prime}$ & 98.4 & $4.89(\mathrm{br} \mathrm{d}, 3.5)$ \\
2 & n.d. & - & $2^{\prime}$ & 30.7 & $2.04(\mathrm{~m}) 1.79(\mathrm{td}, 12.3,3.6)$ \\
3 & 159.9 & - & $3^{\prime}$ & 75.0 & $3.43(\mathrm{~m})$ \\
4 & 189.2 & - & $3^{\prime} \alpha$ & 57.1 & $3.24(\mathrm{~s})$ \\
5 & 48.9 & $3.29(\mathrm{~m}) 2.98(\mathrm{~d}, 16.2)$ & $4^{\prime}$ & 73.9 & - \\
6 & 78.2 & - & $5^{\prime}$ & 67.5 & $4.41(\mathrm{~m})$ \\
7 & 198.7 & - & $6^{\prime}$ & 16.5 & $1.10(\mathrm{~m})$ \\
8 & 77.7 & $3.64(\mathrm{~d}, 10.1)$ & $7^{\prime}$ & 69.8 & $5.27(\mathrm{quart} ., 6.8)$ \\
9 & 69.2 & $3.48(\mathrm{~m})$ & $8^{\prime}$ & 16.4 & $1.18(\mathrm{~d}, 6.7)$ \\
10 & 74.5 & $4.08(\mathrm{br} \mathrm{t})$ & $9^{\prime}$ & 175.9 & - \\
11 & 70.7 & $4.66(\mathrm{dd}, 10.2,1.8)$ & $10^{\prime}$ & 41.5 & $2.38(\mathrm{~m})$ \\
12 & 71.9 & $4.00(\mathrm{dt}, 9.9,3.4)$ & $11^{\prime}$ & 26.9 & $1.60(\mathrm{~m}) 1.45(\mathrm{~m})$ \\
13 & 62.9 & $3.77(\mathrm{~m})$ & $12^{\prime}$ & 12.2 & $0.88(\mathrm{t}, 7.0)$ \\
14 & 170.8 & - & $13^{\prime}$ & 17.5 & 1.09 \\
15 & 21.2 & $1.96(\mathrm{~s})$ & $1^{\prime \prime}$ & 168.5 & - \\
\hline & & $2^{\prime \prime}$ & 80.2 & $5.04(\mathrm{~d}, 7.5)$ \\
& & $3^{\prime \prime}$ & 49.8 & $4.36(\mathrm{~m})$ \\
& & $4^{\prime \prime}$ & 16.5 & $1.10(\mathrm{~m})$ \\
& & $5^{\prime \prime}$ & 167.8 & - \\
& & $1^{\prime \prime \prime}$ & 172.2 & - \\
& & $2^{\prime \prime \prime}$ & 52.6 & $4.46(\mathrm{~m})$ \\
& & $3^{\prime \prime \prime}$ & 34.2 & $3.62(\mathrm{~m}) 3.26(\mathrm{~m})$ \\
& & $4^{\prime \prime \prime}$ & 170.3 & - \\
& & $5^{\prime \prime \prime}$ & 23.2 &
\end{tabular}




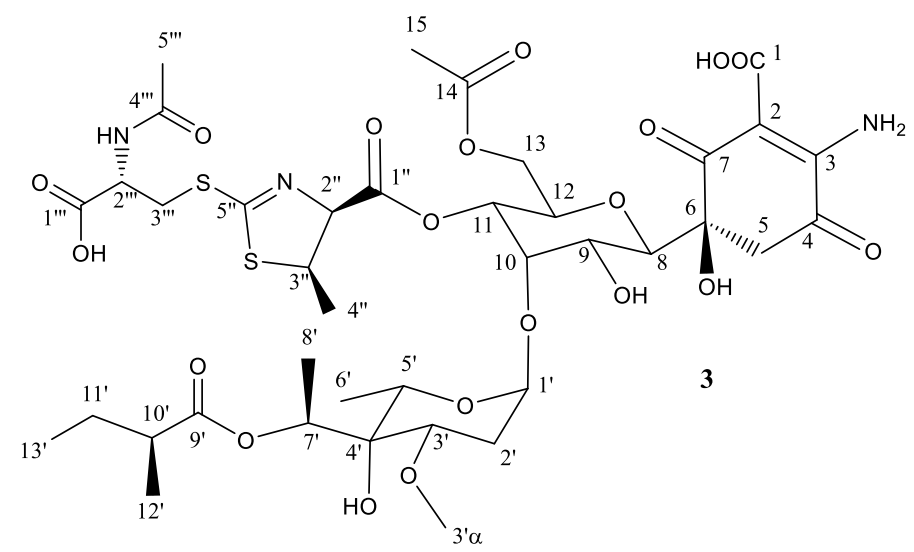

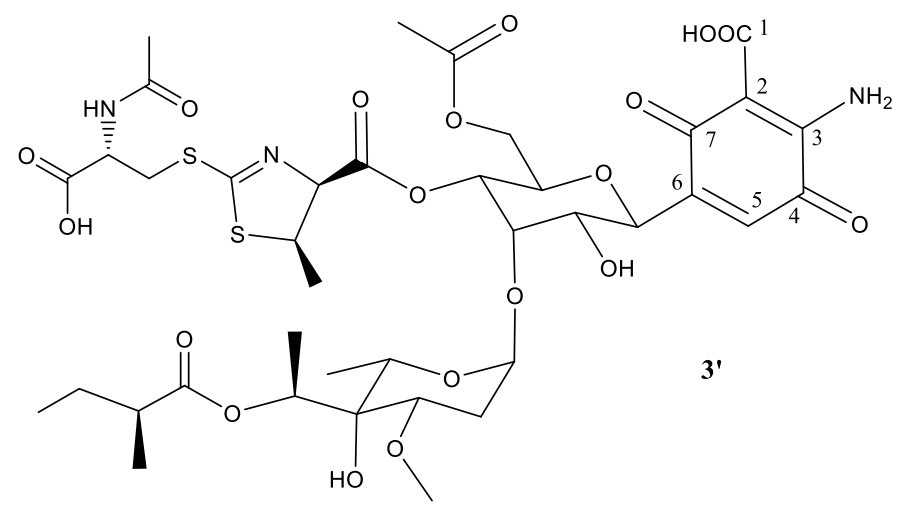

Figure 4. Structure of compound 3 deduced from ${ }^{1} \mathrm{H}$ - and ${ }^{13} \mathrm{C}-\mathrm{NMR}$ data and proposed structure of secondary product compound $\mathbf{3}^{\prime}$ after abstraction of one molecule of $\mathrm{H}_{2} \mathrm{O}$.

The secondary component $\mathbf{3}^{\prime}$ (Figure 4 ) is proposed to be the dehydration product obtained by a water loss at positions 5 and 6 , generating the corresponding quinone ring, as previously mentioned for $\mathbf{1}^{\prime}$ and $\mathbf{2}^{\prime}$.

Peak 4 (Figure 1) was obtained as a brownish amorphous powder. The LC-DAD-HRMS run revealed the presence of two main components with retention mobility of 3.81 and $4.09 \mathrm{~min}$, respectively (Figure S19). Both components showed identical DAD and HRMS (Figures S20 and S21) spectra as the components detected in peak 1 . Thus, having the same molecular formula, it is likely that in this peak there are two stereoisomers of the compounds present in peak 3 , in a similar manner as it occurred for the compounds found in peaks 1 and 2.

To establish the identity of the main compound 4 (Table 4, Figure 5), a ${ }^{1} \mathrm{H}$ NMR spectrum and a set of 2D NMR spectra (including COSY, TOCSY, NOESY, HSQC and HMBC) were acquired (Figures S22 and S23). The chemical shifts observed for peak 4 were almost identical to those of peak 1, except for the fatty acid. This provided direct evidence that the connectivity and configuration of compound 4 is identical to that of compound 3, except for positions $2^{\prime \prime}$ and $3^{\prime \prime}$ which display an anti relationship (the same situation already found for compounds $\mathbf{1}$ and 2 ) further confirmed by the coupling constant measured for $\mathrm{H}-2^{\prime \prime}(4.7 \mathrm{~Hz})$.

The secondary component $4^{\prime}$ (Figure 5) is proposed to be the dehydration product obtained by a water loss at positions 5 and 6 , thus generating the corresponding quinone ring for as in compounds $\mathbf{1}^{\prime}, \mathbf{2}^{\prime}$, and $\mathbf{3}^{\prime}$. 
Table 4. NMR data ( $\delta$ in ppm) for compound 4 (DMSO- $d_{6}, 500 \mathrm{MHz}, 24^{\circ} \mathrm{C}$ ). Carbon chemical shifts derived from HSQC and HMBC spectra.

\begin{tabular}{cccccc}
\hline Position & $\boldsymbol{\delta}\left({ }^{\mathbf{1 3}} \mathbf{C}\right)$ & $\boldsymbol{\delta}\left({ }^{\mathbf{1}} \mathbf{H}\right),(\mathbf{M u l t}, \boldsymbol{J}$ in $\mathbf{H z})$ & Position & $\boldsymbol{\delta}\left({ }^{\mathbf{1 3}} \mathbf{C}\right)$ & $\boldsymbol{\delta}\left({ }^{\mathbf{1}} \mathbf{H}\right),(\mathbf{M u l t}, \boldsymbol{J}$ in $\mathbf{H z})$ \\
\hline 1 & n.d. & - & $1^{\prime}$ & 98.4 & $4.89(\mathrm{~m})$ \\
2 & 100.0 & - & $2^{\prime}$ & 30.7 & $2.05(\mathrm{~m}) 1.79(\mathrm{~m})$ \\
3 & 160.0 & - & $3^{\prime}$ & 75.0 & $3.44(\mathrm{~m})$ \\
4 & 189.2 & - & $3^{\prime} \alpha$ & 57.1 & $3.24(\mathrm{~s})$ \\
5 & 48.9 & $3.27(\mathrm{~m}) 2.99(\mathrm{~m})$ & $4^{\prime}$ & 73.9 & - \\
6 & 78.3 & - & $5^{\prime}$ & 67.4 & $4.41(\mathrm{~m})$ \\
7 & 198.7 & - & $6^{\prime}$ & 16.4 & $1.10(\mathrm{~m})$ \\
8 & 77.6 & $3.62(\mathrm{~d}, 9.8)$ & $7^{\prime}$ & 69.8 & $5.27(\mathrm{quart} ., 6.8)$ \\
9 & 69.2 & $3.46(\mathrm{~m})$ & $8^{\prime}$ & 16.4 & $1.18(\mathrm{~d}, 6.7)$ \\
10 & 74.6 & $4.01(\mathrm{br} \mathrm{t})$ & $9^{\prime}$ & 175.9 & - \\
11 & 70.5 & $4.58(\mathrm{dd}, 10.1,2.0)$ & $10^{\prime}$ & 41.5 & $2.37(\mathrm{~m})$ \\
12 & 72.0 & $3.97(\mathrm{~m})$ & $11^{\prime}$ & 26.9 & $1.60(\mathrm{~m}) 1.44(\mathrm{~m})$ \\
13 & 63.0 & $3.76(\mathrm{~m})$ & $12^{\prime}$ & 12.2 & $0.88(\mathrm{t}, 7.0)$ \\
14 & 171.0 & - & $13^{\prime}$ & 17.6 & $1.10(\mathrm{~d}, 6.8)$ \\
15 & 21.2 & $1.97(\mathrm{~s})$ & $1^{\prime \prime}$ & 169.4 & - \\
\hline & & $2^{\prime \prime}$ & 83.2 & $4.90(\mathrm{~d}, 4.7)$ \\
& & $3^{\prime \prime}$ & 51.1 & $4.25(\mathrm{~m})$ \\
& & $4^{\prime \prime}$ & 22.5 & $1.37(\mathrm{~m})$ \\
& & $5^{\prime \prime}$ & 168.0 & - \\
& & $1^{\prime \prime \prime}$ & 172.3 & - \\
& & $2^{\prime \prime \prime}$ & 52.2 & $4.51(\mathrm{~m})$ \\
& & $3^{\prime \prime \prime}$ & 34.3 & $3.62(\mathrm{~m}) 3.29(\mathrm{~m})$ \\
& & $4^{\prime \prime \prime}$ & 170.3 & - \\
& & $5^{\prime \prime \prime}$ & 23.1 & $1.85(\mathrm{~s})$ \\
\hline
\end{tabular}

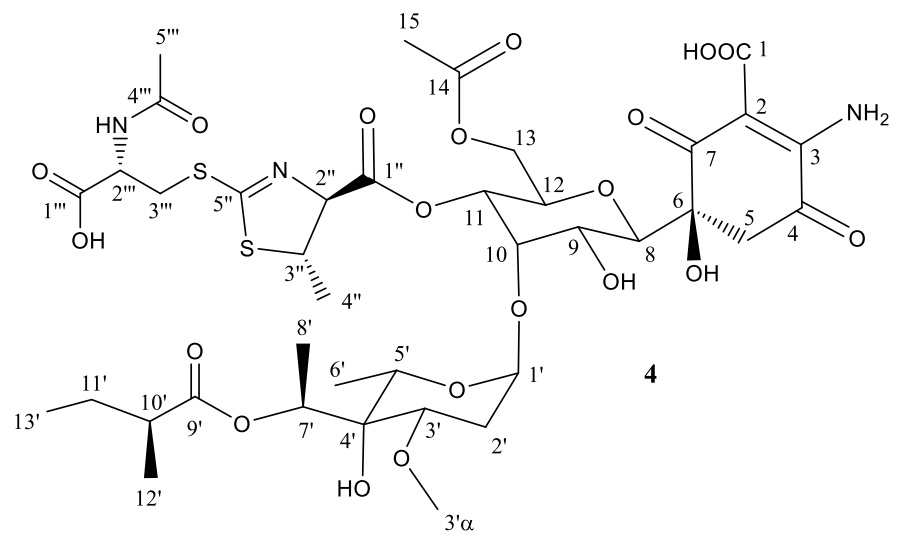

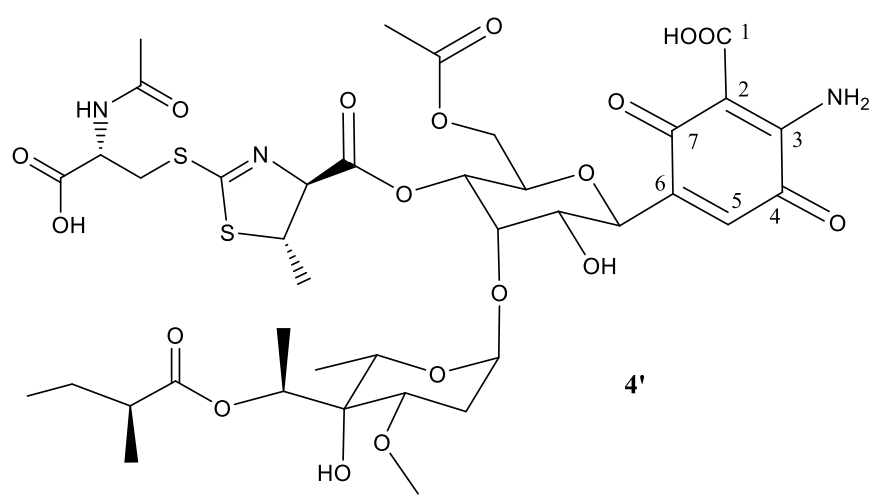

Figure 5. Structure of compound 4 deduced from ${ }^{1} \mathrm{H}$ - and ${ }^{13} \mathrm{C}-\mathrm{NMR}$ data and proposed structure of secondary product compound $4^{\prime}$ elimination of one molecule of $\mathrm{H}_{2} \mathrm{O}$. 
Repeated attempts to obtain pure samples of compounds 1, 2, 3, and 4 resulted in a new mixture containing the compounds $\mathbf{1}^{\prime}, \mathbf{2}^{\prime}, \mathbf{3}^{\prime}$, and $\mathbf{4}^{\prime}$ that appeared during the analysis process due to elimination of one molecule of $\mathrm{H}_{2} \mathrm{O}$ in each case. These results are in concordance with previous reports on the spontaneous dehydration of paulomycin A in solution that is slowly converted into its quinone form, paulomycinone A $[19,20]$. Dehydration of paulomycins occurs even when leaving the compounds in solution in aqueous media at neutral $\mathrm{pH}$, being therefore difficult to avoid [20]. The dehydration of antibiotics $273 \mathrm{a}_{2 \alpha}$ and $273 \mathrm{a}_{2 \beta}$ and paldimycin $\mathrm{A}$ and $\mathrm{B}$ to the corresponding quinones has been also reported previously [14], as well as the same modification of paulomycin G obtained from Micromonospora matsumotoense M-412 [21]. The quinone derivatives of members of the paulomycin family of antibiotics have been reported to lack antibiotic activity [14].

\subsection{Biological Activity of Novel Paulomycins}

The antibacterial activity of freshly purified thiazole derivatives of antibiotics $273 a_{2 \alpha}$ and $273 a_{2 \beta}$ compounds 1-4, lacking apparently any traces of the dehydrated secondary compounds $\mathbf{1}^{\prime}-\mathbf{4}^{\prime}$, was evaluated against Gram-positives Staphylococcus aureus and S. epidermidis; Gram-negatives Escherichia coli and Klebsiella pneumoniae; and yeast Candida albicans, showing the minimal inhibitory concentrations (MIC) depicted in Table 5. All compounds were found active against Gram-positives, in particular 3 and 4 derived from paulomycin A. However, in all cases the levels of activity were lower than parental compounds paulomycin A (5) and B (6). Surprisingly, the four novel thiazole moiety-containing paulomycins, in particular compound 3, showed slight activity against Gram-negatives E. coli and K. pneumonia, and inhibitory activity totally absent in paulomycin A (5) or B (6) [11,14]. None of the compounds tested showed inhibitory activity against $C$. albicans.

Table 5. Antibiotic activity of compounds 1-6 represented as minimal inhibitory concentration (MIC) in $\mu \mathrm{g} / \mathrm{mL}$. Paulomycin A (5) and B (6) were included as controls.

\begin{tabular}{ccccccc}
\hline \multicolumn{7}{c}{ MIC $(\boldsymbol{\mu g} / \mathbf{m L})$} \\
\hline Microorganism & $\mathbf{1}$ & $\mathbf{2}$ & $\mathbf{3}$ & $\mathbf{4}$ & $\mathbf{5}$ & $\mathbf{6}$ \\
\hline S. aureus & 75 & 75 & 37.5 & 25 & $<2.34$ & $<2.34$ \\
S. epidermidis & 50 & 50 & 18.75 & 12.5 & $<2.34$ & $<2.34$ \\
E. coli & 150 & 150 & 75 & 100 & $>200$ & $>200$ \\
K. pneumoniae & 150 & 150 & 100 & 100 & $>200$ & $>200$ \\
C. albicans & 200 & $>200$ & 200 & $>200$ & $>200$ & $>200$ \\
\hline
\end{tabular}

All the new compounds present in each peak were tested for their cytotoxic activity against human tumor cell lines HT29, A549, MDA-MB-231, AGS, HL-60, CAPAN, and A2780, as well as a mouse nonmalignant cell line NIH/3T3. These compounds showed no cytotoxic activity against any of the cell lines under the selected cutoff level of $10 \mu \mathrm{M}$.

\subsection{Stability of Novel Paulomycins in Culture}

In a previous work we reported that paulomenols A and B, contrary to what had been speculated before [12], were not intermediates in the biosynthesis of paulomycins A and B but instead degradation products by loss of the paulic acid moiety [5]. Since paulomenols lack antibacterial activity while $N$-acetyl-L-cysteine containing antibiotics $273 \mathrm{a}_{2 \alpha}$ and $273 \mathrm{a}_{2 \beta}$, paldimycin A and B [12] and thiazole derivatives of antibiotics $273 a_{2 \alpha}$ and $273 a_{2 \beta}$ (compounds 1-4) retain the antibacterial activity, in particular compounds 3 and 4 derived from paulomycin $\mathrm{A}$, we wonder if the incorporation of the $N$-acetyl-L-cysteine moiety could represent a strategy to stabilize the structure-activity of paulomycins. This question was addressed by a feeding experiment using compound 3 and the non-producing deletion mutant S. albus B29 [5] as biotransformation host. We fed compound 3 (apparently lacking any trace containing compound $\mathbf{3}^{\prime}$ ) to this strain after $48 \mathrm{~h}$ of growth in R5A. In this medium paulomycins and paulomenols are produced by S. albus J1074 but peaks $1-4$ are not produced 
or produced in such low amounts that they cannot be spotted. After further $48 \mathrm{~h}$, we could not observe conversion of compound 3 into the corresponding paulomycin B or paulomenol B (Figure 6). On the other hand, no significant conversion of compound 3 into $3^{\prime}$ was observed. The same results were obtained using compounds 1 (Figure S24), 2 (Figure S25), and 4 (Figure S26). These experiments demonstrate that compounds 1-4 are more stable in culture than the corresponding paulomycins. Furthermore, new feeding experiments with S. albus B29 using paulomycin B (6) and paulomycin A (5) as substrates confirmed the degradation of them into inactive paulomenol B (8) and A (7), as previously reported [5], but also their partial bioconversion into active compound 2 (Figure S27) and compound 3 (Figure S28), respectively.

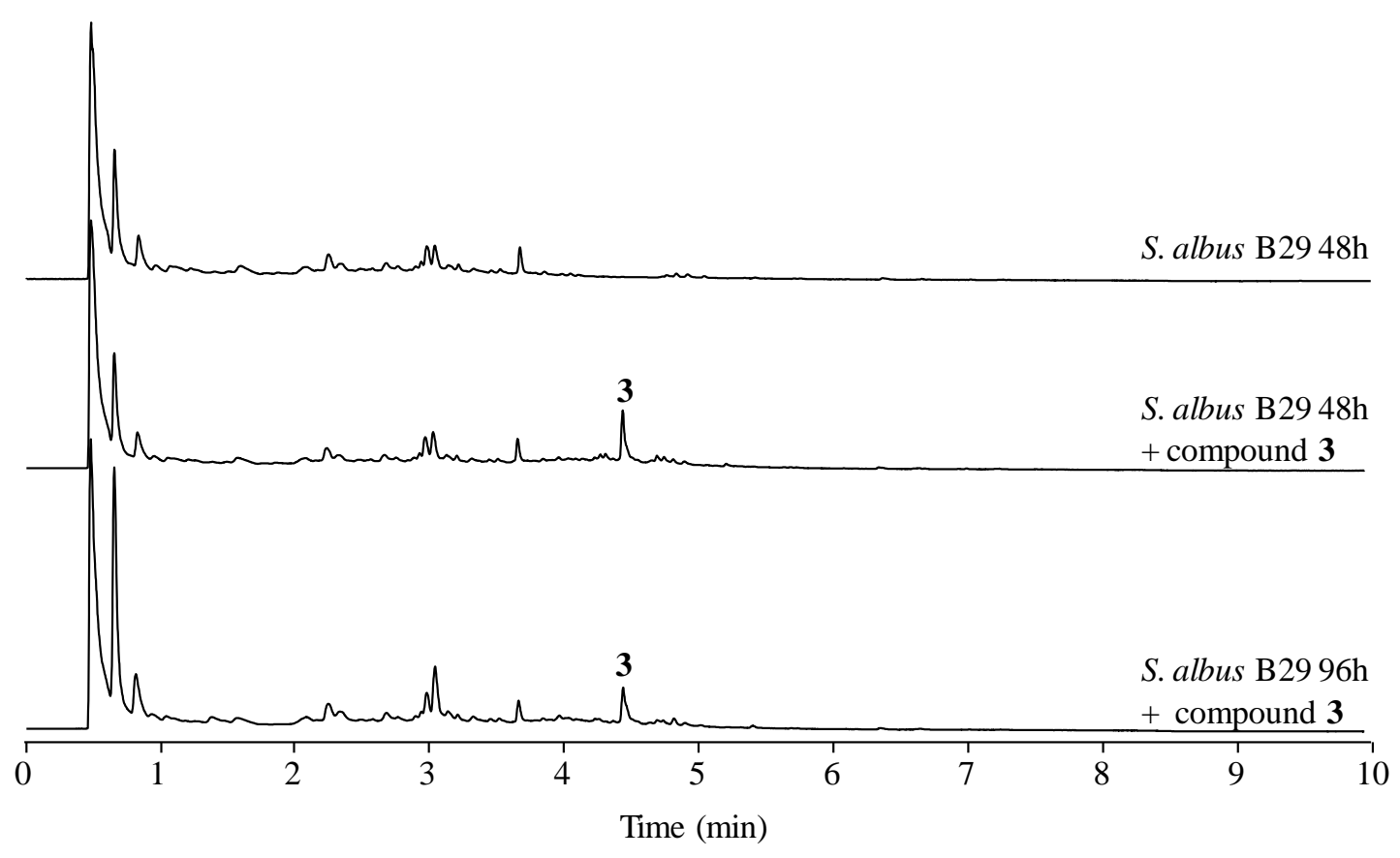

Figure 6. UPLC chromatograms, monitored at $238 \mathrm{~nm}$, of mutant S. albus B29 grown in R5A liquid medium and fed with $50 \mu \mathrm{g} \mathrm{mL}-1$ of compound 3 .

\section{Discussion}

The presence of $\mathrm{N}$-acetyl-L-cysteine moieties as structural elements of secondary metabolite compounds produced by actinomycetes has been reported not only in the case of paulomycin A and B derivatives antibiotics $273 a_{2 \alpha}$ and $273 a_{2 \beta}$, and paldimycin A and B [13,14], but also in other compounds with different biosynthetic origins such as lactacystin [22], phenazine antibiotic SB 212305 [23], seongomycin [24], naphthomycins I and J [25], cinnabaramides F and G [26], piceamycin $N$-acetyl-L-cysteine adduct [27], coelimycin P1 [28], homoseongomcin [29], cyslabdan [30], and argimycins PI and PII [31]. In some of these examples, such as SB 212305 and piceamycin, the presence of the $\mathrm{N}$-acetyl-L-cysteine moiety has been associated with a loss of biological activity, antibiotics (in the case of SB 212305 [23]), and antibiotics and cytotoxic (in the case of piceamycin $\mathrm{N}$-acetyl-L-cysteine adduct [27]). However, the presence of the $\mathrm{N}$-acetyl-L-cysteine moiety has no effect on the cytotoxic activity of lactacystin [22] and cinnabaramides F and G [26], or on potentiates imipenem activity against methicillin-resistant Staphylococcus aureus (MRSA) in the case of cyslabdan [32]. The incorporation of the $N$-acetyl-L-cysteine moiety during the biosynthesis of cyslabdan has been shown to occur by the excretion of a labdane-type epoxide intermediate using a mycothiol MSH-mediated xenobiotic detoxification [30]. A similar mechanism has been proposed for the biosynthesis of seongomycin, naphthomycin J, lactacystin, and homoseongomycin $[29,30]$. 
In the case of paulomycin A and B derivatives: antibiotics $273 \mathrm{a}_{2 \alpha}$ and $273 \mathrm{a}_{2 \beta}$, paldimycin A and $B$, and thiazole derivatives of antibiotics $273 a_{2 \alpha}$ and $273 a_{2 \beta}$ (compounds 1-4), the incorporation of $\mathrm{N}$-acetyl-L-cysteine moieties via a thioester bond, and the subsequent intramolecular cyclization of the paulic acid to generate a thiazole heterocycle in compounds 1-4, appears as a stabilization mechanism (probably by MSH-mediated detoxification) conducing to more stable structures in culture that retain antibiotic activity (improved against Gram-negatives), in opposition to the instability of paulomycins that degrade into inactive paulomenols [5] (Figure 7).

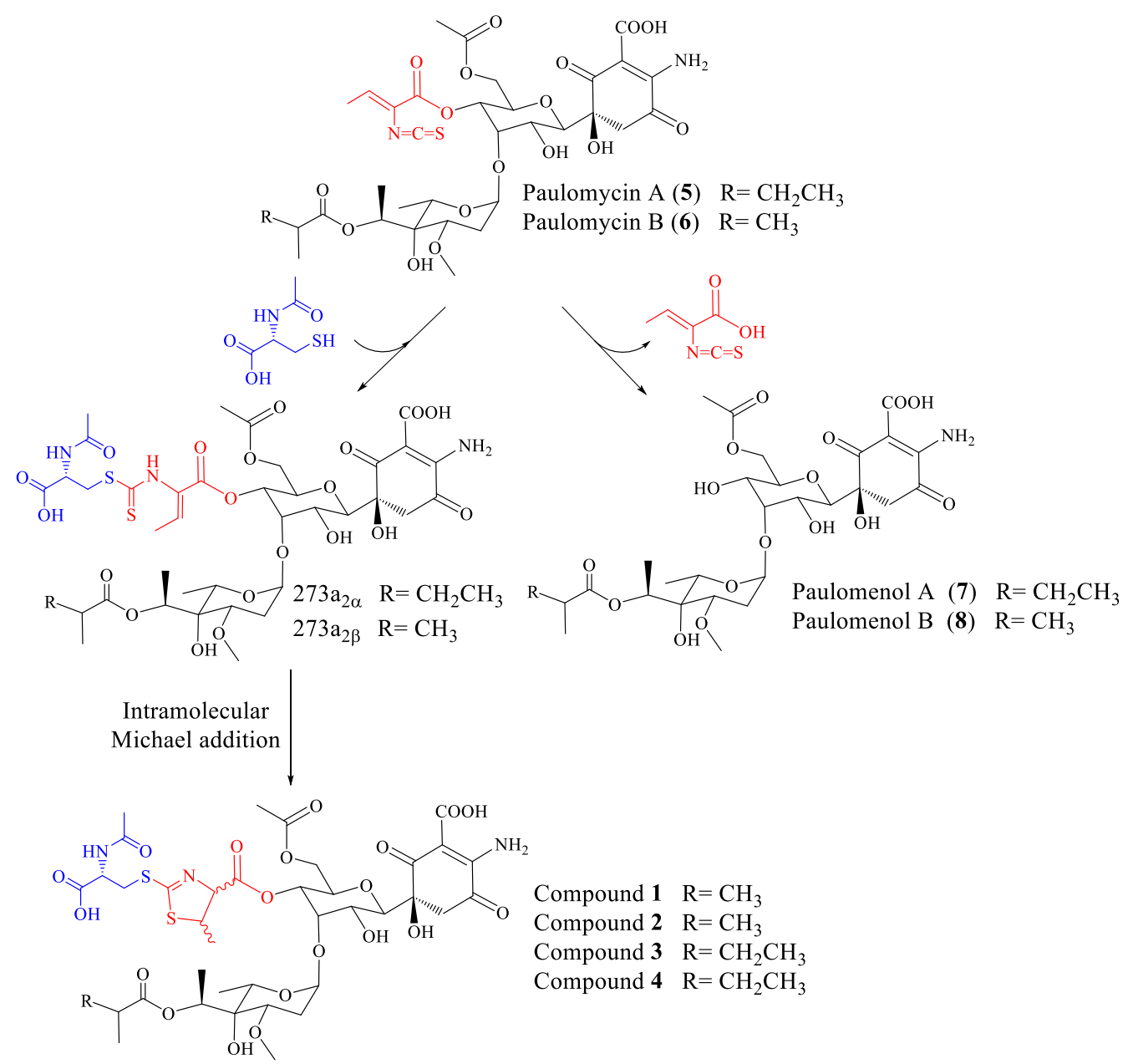

Figure 7. Fate of paulomycins in culture conditions leading to their degradation into paulomenols or to their conversion into antibiotics $273 \mathrm{a}_{2}$ and thiazole derivatives compounds $\mathbf{1 - 4}$ in S. albus J1074.

\section{Materials and Methods}

\subsection{Microorganisms and Culture Media}

Bacterial strains used in this work were S. albus J1074 [1] and S. albus B29 [5]. Growth medium for S. albus was tryptone soy broth (TSB), MA medium was used for sporulation, and MFE medium [8] as regular production medium of compounds 1-4. R5A medium [33] was used for bioconversion experiments. TSB or YDP [34] were used to determine the minimal inhibitory concentration (MIC) of compounds 1-4 against bacteria or fungi, respectively. 


\subsection{Isolation and Structural Characterization of Compounds}

Whole cultures of S. albus J1074 grown in MFE medium during $120 \mathrm{~h}$ at $30{ }^{\circ} \mathrm{C}$ were extracted with ethyl acetate containing formic acid (1\%) and analyzed by UPLC and LC-MS for the production of paulomycins, following previously described methods $[5,34]$. Reversed phase chromatography was performed in an Acquity UPLC instrument fitted with a BEH C18 column $(1.7 \mu \mathrm{m}, 2.1 \times 100 \mathrm{~mm}$, Waters, Cardanyola del Vallés, Spain). Samples were eluted with 10\% acetonitrile for $1 \mathrm{~min}$, followed by a linear gradient from 10 to $100 \%$ acetonitrile over $9 \mathrm{~min}$, at a flow rate of $0.5 \mathrm{~mL} / \mathrm{min}$ and a column temperature of $35^{\circ} \mathrm{C}$. For HPLC-MS analysis, an Alliance chromatographic system coupled to a ZQ4000 mass spectrometer and a SunFire C18 column $(3.5 \mu \mathrm{m}, 2.1 \times 150 \mathrm{~mm}$, Waters $)$ was used. Solvents were the same as above and elution was performed with an initial isocratic hold with $10 \%$ acetonitrile during 4 min followed by a linear gradient from 10 to $88 \%$ acetonitrile over $26 \mathrm{~min}$, at $0.25 \mathrm{~mL} / \mathrm{min}$. MS analysis were done by electrospray ionization in the positive mode, with a capillary voltage of $3 \mathrm{kV}$ and a cone voltage of $20 \mathrm{~V}$. Detection and spectral characterization of peaks was performed in both cases by photodiode array detection in the range from 200 to $500 \mathrm{~nm}$ using Empower software (Waters) to extract bidimensional chromatograms at different wavelengths, depending on the spectral characteristics of the desired compound.

Isolation of peaks 1-4 was performed following the procedure previously described for isolation of paulomycins [35]. S. albus J1074 was grown in MFE medium at $30^{\circ} \mathrm{C}$ for $120 \mathrm{~h}$ in five Erlenmeyer flasks (2 L), each containing $400 \mathrm{~mL}$ of medium; each flask was inoculated with spores and incubated in an orbital shaker at $250 \mathrm{rpm}$. Purification of the four peaks was performed by preparative HPLC using as solvent $57 \%$ methanol and $0.1 \%$ TFA in water in isocratic conditions optimized for each peak at $5 \mathrm{~mL} / \mathrm{min}$. After every purification step, the collected peaks were diluted with methanol and concentrated by solid-phase extraction (Sep-Pak C18, Waters) to remove acid traces that could affect the stability of the purified molecules. Finally, the compounds were dissolved in a 50\% mixture of tert-butanol and $\mathrm{H}_{2} \mathrm{O}$-milliQ and lyophilized. Yield and productivity of each compound was as follows: 1, $1.2 \mathrm{mg}(0.6 \mu \mathrm{g} / \mathrm{mL}) ; 2,1.2 \mathrm{mg}(0.6 \mu \mathrm{g} / \mathrm{mL}) ; 3,0.5 \mathrm{mg}(0.25 \mu \mathrm{g} / \mathrm{mL})$; and 4, $0.5 \mathrm{mg}(0.25 \mu \mathrm{g} / \mathrm{mL})$.

The structural elucidation of compounds 1-4 was carried out at Fundación Medina (Granada, Spain) by a combination of LC-DAD-HRMS analysis carried out on an Agilent 1200 Rapid Resolution HPLC system coupled to a Bruker maXis mass spectrometer (Rivas-Vaciamadrid, Spain). For the NMR analyses, compounds 1-4 were dissolved in deuterated DMSO (DMSO-d6) and transferred to a $1.7 \mathrm{~mm}$ tube. Acquisitions were carried out on a Bruker AVANCE III $500 \mathrm{MHz}$ spectrometer (Rivas-Vaciamadrid, Spain) equipped with a $1.7 \mathrm{~mm}$ TCI Microcryoprobe. All spectra were registered at $24^{\circ} \mathrm{C}$.

Peak 1: brownish amorphous powder; compound 1: for ${ }^{1} \mathrm{H}$ and ${ }^{13} \mathrm{C}$ NMR data see Table 1; HRESIMS $m / z$ 936.2739 [M + H] $]^{+}$(calcd. for $\mathrm{C}_{38} \mathrm{H}_{54} \mathrm{~N}_{3} \mathrm{O}_{20} \mathrm{~S}_{2}{ }^{+}=936.2739$ ); compound $\mathbf{1}^{\prime}$ (product $\mathbf{1}$ after abstraction of one molecule of $\mathrm{H}_{2} \mathrm{O}$ ): HRESIMS m/z 918.2636 [M + H] $]^{+}$(calcd. for $\mathrm{C}_{38} \mathrm{H}_{52} \mathrm{~N}_{3} \mathrm{O}_{19} \mathrm{~S}_{2}{ }^{+}$ $=918.2631)$.

Peak 2: brownish amorphous powder; compound 2: for ${ }^{1} \mathrm{H}$ and ${ }^{13} \mathrm{C}$ NMR data see Table 2; HRESIMS m/z 936.2737 [M + H] $]^{+}$(calcd. for $\mathrm{C}_{38} \mathrm{H}_{54} \mathrm{~N}_{3} \mathrm{O}_{20} \mathrm{~S}_{2}{ }^{+}=$936.2739); compound 2' (product 2 after abstraction of one molecule of $\mathrm{H}_{2} \mathrm{O}$ ): HRESIMS m/z $918.2630[\mathrm{M}+\mathrm{H}]^{+}$(calcd. for $\mathrm{C}_{38} \mathrm{H}_{52} \mathrm{~N}_{3} \mathrm{O}_{19} \mathrm{~S}_{2}{ }^{+}$ $=918.2631$.

Peak 3: brownish amorphous powder; compound 3: for ${ }^{1} \mathrm{H}$ and ${ }^{13} \mathrm{C}$ NMR data see Table 3; HRESIMS $m / z$ 950.2893 [M + H] $]^{+}$(calcd. for $\mathrm{C}_{39} \mathrm{H}_{56} \mathrm{~N}_{3} \mathrm{O}_{20} \mathrm{~S}_{2}{ }^{+}=936.2893$ ); compound 3' (product 3 after abstraction of one molecule of $\mathrm{H}_{2} \mathrm{O}$ ): HRESIMS m/z $932.2782[\mathrm{M}+\mathrm{H}]^{+}$(calcd. for $\mathrm{C}_{39} \mathrm{H}_{54} \mathrm{~N}_{3} \mathrm{O}_{19} \mathrm{~S}_{2}{ }^{+}$ $=932.2787$ ).

Peak 4: brownish amorphous powder; compound 4: for ${ }^{1} \mathrm{H}$ and ${ }^{13} \mathrm{C}$ NMR data see Table 4; HRESIMS m/z 950.2899 [M + H] $]^{+}$(calcd. for $\mathrm{C}_{39} \mathrm{H}_{56} \mathrm{~N}_{3} \mathrm{O}_{20} \mathrm{~S}_{2}{ }^{+}=936.2893$ ); compound $4^{\prime}$ (product 4 after abstraction of one molecule of $\mathrm{H}_{2} \mathrm{O}$ ): HRESIMS m/z $932.2782[\mathrm{M}+\mathrm{H}]^{+}$(calcd. for $\mathrm{C}_{39} \mathrm{H}_{54} \mathrm{~N}_{3} \mathrm{O}_{19} \mathrm{~S}_{2}{ }^{+}$ =932.2787). 


\subsection{Biological Activity}

The antibacterial activity of paulomycin derivatives, compounds 1-4, was analyzed via determination of the minimal inhibitory concentration (MIC) against Escherichia coli, Klebsiella pneumoniae, Staphylococcus aureus, and Staphylococcus epidermidis. The antifungal activity of paulomycin derivatives was tested against Candida albicans. MIC was evaluated using two serial dilutions of each compound, from $200 \mu \mathrm{g} / \mathrm{mL}$ to $3.12 \mu \mathrm{g} / \mathrm{mL}$ and from $150 \mu \mathrm{g} / \mathrm{mL}$ to $2.34 \mu \mathrm{g} / \mathrm{mL}$, and bacterial cultures with an initial $\mathrm{OD}_{600}$ of 0.3 . Growth on the microtiter plates was determined during $24 \mathrm{~h}$ of incubation at $37^{\circ} \mathrm{C}$.

The cytotoxic activity of compounds 1-4 was tested against the following human tumor cell lines: colon adenocarcinoma (HT29), non-small cell lung cancer (A549), breast adenocarcinoma (MDA-MB-231), gastric carcinoma (AGS), promyelocytic leukemia (HL-60), pancreatic adenocarcinoma (CAPAN), and ovarian carcinoma (A2780). Mouse embryonic fibroblast cell line NIH/3T3 was used as control to evaluate cytotoxicity against non-malignant cells. Cells were previously grown for a week on DMEM-10\% FBS medium, then aliquoted to 5000 cells per well in 96-well plates using the Cell counting kit-8-(96992) (Sigma-Aldrich, Tres Cantos, Spain) and grown for an extra $24 \mathrm{~h}$. Compounds were dissolved in DMSO, keeping in mind that final concentration of DMSO in the assays should be kept at $0.1 \%$. After the incubation, $10 \mu \mathrm{L}$ of compound (in diverse concentrations) were added to each well and incubated for another $48 \mathrm{~h}$. Lastly, $10 \mu \mathrm{L}$ of CCK-8 reagent (Sigma-Aldrich) were added, left to develop for $2 \mathrm{~h}$ in the incubator, and measured at $450 \mathrm{~nm}$ using an Elisa Bio-tek ELx 800 (BioTek, Winooski, VT, USA).

Supplementary Materials: ${ }^{1} \mathrm{H}-,{ }^{13} \mathrm{C}-\mathrm{NMR}, \mathrm{HMBC}, \mathrm{HSQC}$, and NOESY spectra of compounds $\mathbf{1 - 4}$ are available as Supplementary Materials.

Acknowledgments: This research was supported by the Spanish Ministry of Economy and Competitiveness Grants, MINECO (BIO2012-33596 to J.A.S. and PIM2010EEI-00752 to C.M.), and "Apoyo a grupos de excelencia", Principado de Asturias-FEDER (FC-15-GRUPIN14-014). J.F.-D.1.H. predoctoral fellowship of the Spanish Ministry of Economy and Competitiveness, MINECO (BES-2013-064704). We thank Fundación Bancaria Cajastur for financial support to C.O. We also like to thank Fernando Reyes from Fundación Medina for technical support in the structural elucidation of compounds.

Author Contributions: J.F.-D.1.H. performed the experiments. J.F.-D.1.H. and C.O. analyzed the data. C.M. and J.A.S. consulted for the project. J.A.S. and C.O. conceived and designed the experiments. C.O. wrote the manuscript. All the authors reviewed and approved the manuscript.

Conflicts of Interest: The authors declare no conflict of interest.

\section{References}

1. Chater, K.F.; Wilde, L.C. Restriction of a bacteriophage of Streptomyces albus G involving endonuclease Sall. J. Bacteriol. 1976, 128, 644-650. [PubMed]

2. Baltz, R.H. Streptomyces and Saccharopolyspora hosts for heterologous expression of secondary metabolite gene clusters. J. Ind. Microbiol. Biotechnol. 2010, 37, 759-772. [CrossRef] [PubMed]

3. Zaburannyi, N.; Rabyk, M.; Ostash, B.; Fedorenko, V.; Luzhetskyy, A. Insights into naturally minimised Streptomyces albus J1074 genome. BMC Genom. 2014, 15. [CrossRef] [PubMed]

4. Myronovskyi, M.; Tokovenko, B.; Brötz, E.; Rückert, C.; Kalinowski, J.; Luzhetskyy, A. Genome rearrangements of Streptomyces albus J1074 lead to the carotenoid gene cluster activation. Appl. Microbiol. Biotechnol. 2014, 98, 795-806. [CrossRef] [PubMed]

5. Olano, C.; García, I.; González, A.; Rodriguez, M.; Rozas, D.; Rubio, J.; Sánchez-Hidalgo, M.; Braña, A.F.; Méndez, C.; Salas, J.A. Activation and identification of five clusters for secondary metabolites in Streptomyces albus J1074. Microb. Biotechnol. 2014, 7, 242-256. [CrossRef] [PubMed]

6. Xu, F.; Nazari, B.; Moon, K.; Bushin, L.B.; Seyedsayamdost, M.R. Discovery of a cryptic antifungal compound from Streptomyces albus J1074 using high-throughput elicitor screens. J. Am. Chem. Soc. 2017. [CrossRef] [PubMed]

7. Majer, J.; Chater, K.F. Streptomyces albus G produces an antibiotic complex identical to paulomycins A and B. J. Gen. Microbiol. 1987, 133, 2503-2507. [CrossRef] [PubMed] 
8. González, A.; Rodríguez, M.; Braña, A.F.; Méndez, C.; Salas, J.A.; Olano, C. New insights into paulomycin biosynthesis pathway in Streptomyces albus J1074 and generation of novel derivatives by combinatorial biosynthesis. Microb. Cell Fact. 2016, 15. [CrossRef] [PubMed]

9. Wiley, P.F. A new antibiotic U-43120 (NSC-163500). J. Antibiot. 1976, 29, 587-589. [CrossRef] [PubMed]

10. Argoudelis, A.D.; Brinkley, T.A.; Brodasky, T.F.; Buege, J.A.; Meyer, H.F.; Mizsak, S.A. Paulomycins A and B. Isolation and characterization. J. Antibiot. 1982, 35, 285-294. [CrossRef] [PubMed]

11. Argoudelis, A.D.; Baczynskyj, L.; Haak, W.J.; Knoll, W.M.; Mizsak, S.A.; Shilliday, F.B. New paulomycins produced by Streptomyces paulus. J. Antibiot. 1988, 41, 157-169. [CrossRef] [PubMed]

12. Argoudelis, A.D.; Baczynskyj, L.; Mizsak, S.A.; Shilliday, F.B. O-demethylpaulomycins A and B, U-77,802 and U-77,803, paulomenols A and B, new metabolites produced by Streptomyces paulus. J. Antibiot. 1988, 41, 1316-1330. [CrossRef] [PubMed]

13. Argoudelis, A.D.; Baczynskyj, L.; Buege, J.A.; Marshall, V.P.; Mizsak, S.A.; Wiley, P.F. Paulomycin-related antibiotics: Paldimycins and antibiotics $273 \mathrm{a}_{2}$. Isolation and characterization. J. Antibiot. 1987, 40, 408-418. [CrossRef] [PubMed]

14. Argoudelis, A.D.; Baczynskyj, L.; Mizsak, S.A.; Shilliday, F.B.; Spinelli, P.A.; DeZwaan, J. Paldimycins A and $B$ and antibiotics $273 a_{2 \alpha}$ and $273 a_{2 \beta}$. Synthesis and characterization. J. Antibiot. 1987, 40, 419-436. [CrossRef] [PubMed]

15. Eliopoulos, G.M.; Reiszner, E.; Moellering, R.C., Jr. In vitro evaluation of the new paulomycin antibiotic paldimycin. Eur. J. Clin. Microbiol. 1987, 6, 306-308. [CrossRef] [PubMed]

16. Olano, C.; Méndez, C.; Salas, J.A. Post-PKS tailoring steps in natural product-producing actinomycetes from the perspective of combinatorial biosynthesis. Nat. Prod. Rep. 2010, 27, 571-616. [CrossRef] [PubMed]

17. Olano, C.; Méndez, C.; Salas, J.A. Molecular insights on the biosynthesis of antitumour compounds by actinomycetes. Microb. Biotechnol. 2011, 4, 144-164. [CrossRef] [PubMed]

18. Zarins-Tutt, J.S.; Barberi, T.T.; Gao, H.; Mearns-Spragg, A.; Zhang, L.; Newman, D.J.; Goss, R.J. Prospecting for new bacterial metabolites: A glossary of approaches for inducing, activating andupregulating the biosynthesis of bacterial cryptic or silent natural products. Nat. Prod. Rep. 2016, 33, 54-72. [CrossRef] [PubMed]

19. Wiley, P.F.; Mizsak, S.A.; Baczynskyj, L.; Argoudelis, A.D. The structure of paulomycin. J. Antibiot. 1984, 37, 1273-1275. [CrossRef] [PubMed]

20. Wiley, P.F.; Mizsak, S.A.; Baczynskyj, L.; Argoudelis, A.D.; Duchamp, D.J.; Watt, W. The structure and chemistry of paulomycin. J. Org. Chem. 1986, 51, 2493-2499. [CrossRef]

21. Sarmiento-Vizcaíno, A.; Braña, A.F.; Pérez-Victoria, I.; Martín, J.; de Pedro, N.; Cruz, M.; Díaz, C.; Vicente, F.; Acuña, J.L.; Reyes, F.; et al. Paulomycin G, a new natural product with cytotoxic activity against tumor cell lines produced by deep-sea sediment derived Micromonospora matsumotoense M-412 from the Avilés canyon in the Cantabrian sea. Mar. Drugs. 2017, 15. [CrossRef] [PubMed]

22. Camery, J.R.; Hong, S.T.; Gould, S.J. Seongomycin: A new sulfur-containing benzo[b]fluorene derived from genes clustered with those for kanamycin biosynthesis. Tetrahedron Lett. 1997, 38, 3139-3142.

23. Gilpin, M.L.; Fulston, M.; Payne, D.; Cramp, R.; Hood, I. Isolation and structure determination of two novel phenazines from a Streptomyces with inhibitory activity against metallo-enzymes, including metallo- $\beta$-lactamase. J. Antibiot. 1995, 48, 1081-1085. [CrossRef] [PubMed]

24. Hooper, A.M.; Rickards, R.W. 3-Amino-5-hydroxybenzoic acid in antibiotic biosynthesis. XI. Biological origins and semisynthesis of thionaphthomycins, and the structures of naphthomycins I and J. J. Antibiot. 1998, 51, 845-851. [CrossRef] [PubMed]

25. Omura, S.; Fujimoto, T.; Otoguro, K.; Matsuzaki, K.; Moriguchi, R.; Tanaka, H.; Sasaki, Y. Lactacystin, a novel microbial metabolite, induces neuritogenesis of neuroblastoma cells. J. Antibiot. 1991, 44, 113-116. [CrossRef] [PubMed]

26. Stadler, M.; Bitzer, J.; Mayer-Bartschmid, A.; Müller, H.; Benet-Buchholz, J.; Gantner, F.; Tichy, H.V.; Reinemer, P.; Bacon, K.B. Cinnabaramides A-G: Analogues of lactacystin and salinosporamide from a terrestrial streptomycete. J. Nat. Prod. 2007, 70, 246-252. [CrossRef] [PubMed]

27. Schulz, D.; Nachtigall, J.; Riedlinger, J.; Schneider, K.; Poralla, K.; Imhoff, J.F.; Beil, W.; Nicholson, G.; Fiedler, H.P.; Süssmuth, R.D. Piceamycin and its $N$-acetylcysteine adduct is produced by Streptomyces sp. GB 4-2. J. Antibiot. 2009, 62, 513-518. [CrossRef] [PubMed] 
28. Gomez-Escribano, J.P.; Song, L.; Fox, D.J.; Yeo, V.; Bibb, M.J.; Challis, G.L. Structure and biosynthesis of the unusual polyketide alkaloid coelimycin P1, a metabolic product of the cpk gene cluster of Streptomyces coelicolor M145. Chem. Sci. 2012, 3, 2716-2720. [CrossRef]

29. Woo, C.M.; Gholap, S.L.; Herzon, S.B. Insights into lomaiviticin biosynthesis. Isolation and structure elucidation of (-)-homoseongomycin. J. Nat. Prod. 2013, 76, 1238-1241. [CrossRef] [PubMed]

30. Ikeda, H.; Shin-Ya, K.; Nagamitsu, T.; Tomoda, H. Biosynthesis of mercapturic acid derivative of the labdane-type diterpene, cyslabdan that potentiates imipenem activity against methicillin-resistant Staphylococcus aureus: Cyslabdan is generated by mycothiol-mediated xenobiotic detoxification. J. Ind. Microbiol. Biotechnol. 2016, 43, 325-342. [CrossRef] [PubMed]

31. Suhui, Y.; Molloy, B.; Braña, A.F.; Zabala, D.; Olano, C.; Cortés, J.; Moris, J.F.; Salas, J.A.; Méndez, C. Identification by genome mining of a type I polyketide gene cluster from Streptomyces argillaceus involved in the biosynthesis of pyridine and piperidine alkaloids argimycins P. Front. Microbiol. 2016, 15. [CrossRef]

32. Fukumoto, A.; Kim, Y.P.; Hanaki, H.; Shiomi, K.; Tomoda, H.; Omura, S. Cyslabdan, a new potentiator of imipenem activity against methicillin-resistant Staphylococcus aureus, produced by Streptomyces sp. K04-0144 II. Biological activities. J. Antibiot. 2008, 61, 7-10. [CrossRef] [PubMed]

33. Fernández, E.; Weissbach, U.; Sánchez Reillo, C.; Braña, A.F.; Méndez, C.; Rohr, J.; Salas, J.A. Identification of two genes from Streptomyces argillaceus encoding glycosyltransferases involved in transfer of a disaccharide during biosynthesis of the antitumor drug mithramycin. J. Bacteriol. 1998, 180, 4929-4937. [PubMed]

34. Ausubel, F.M.; Brent, R.; Kingston, R.E.; Moore, D.D.; Seidman, J.G.; Smith, J.A.; Struhl, K. Current Protocols in Molecular Biology; Current Protocols: Brooklyn, NY, USA, 1994.

35. Braña, A.F.; Rodríguez, M.; Pahari, P.; Rohr, J.; García, L.A.; Blanco, G. Activation and silencing of secondary metabolites in Streptomyces albus and Streptomyces lividans after transformation with cosmids containing the thienamycin gene cluster from Streptomyces cattleya. Arch. Microbiol. 2014, 196, 345-355. [CrossRef] [PubMed]

Sample Availability: Samples of the compounds 1-4 are available from the authors.

(C) 2017 by the authors. Licensee MDPI, Basel, Switzerland. This article is an open access article distributed under the terms and conditions of the Creative Commons Attribution (CC BY) license (http://creativecommons.org/licenses/by/4.0/). 